\title{
Paper
}

\section{Synthesis of Fe-Co-Ni-(B, Si, C) Ferromagnetic High Entropy Amorphous Alloys and Their Thermal and Magnetic Properties}

\author{
Maki SATAKE and Teruo BITOH* \\ Department of Machine Intelligence and Systems Engineering, Faculty of Systems Science and Technology, Akita Prefectural University, \\ Yurihonjo 015-0055, Japan.
}

Received December 8, 2017; Revised January 8, 2018; Accepted February 20, 2018

\begin{abstract}
The ferromagnetic Fe-Co-Ni-(B, C, Si) high entropy alloys (HEAs) with an amorphous structure were prepared by single-roller melt-spinning method and evaluated their thermal and magnetic properties. The single amorphous phase is obtained both the $\mathrm{Fe}_{25} \mathrm{Co}_{25} \mathrm{Ni}_{25}\left(\mathrm{~B}_{1-x} \mathrm{Si}_{x}\right)_{25}$ HEAs and $\mathrm{Fe}_{75}\left(\mathrm{~B}_{1-x} \mathrm{Si}_{x}\right)_{25}$ alloys $(x=0.3,0.5,0.7)$. It was confirmed that the HEAs with $x=0.3$ and 0.5 exhibits the glass transition prior to crystallization. On the other hands, the $\mathrm{Fe}_{75}(\mathrm{~B}, \mathrm{Si})_{25}$ alloys do not show the glass transition. The critical thickness for the amorphous formation is larger than $0.23 \mathrm{~mm}$ for the $\mathrm{Fe}_{25} \mathrm{Co}_{25} \mathrm{Ni}_{25}\left(\mathrm{~B}_{0.7} \mathrm{Si}_{0.3}\right)_{25}$ HEA and is approximately $0.10 \mathrm{~mm}$ for the $\mathrm{Fe}_{75}\left(\mathrm{~B}_{0.7} \mathrm{Si}_{0.3}\right)_{25}$ alloy. Therefore, the HEAs have much larger glass-forming ability than that of the conventional Fe-based amorphous alloys. The similar results were obtained in the $\mathrm{Fe}_{25} \mathrm{Co}_{25} \mathrm{Ni}_{25}\left(\mathrm{~B}_{1-x} \mathrm{C}_{x}\right)_{25} \mathrm{HEAs}$. On the other hand, the amorphous phase could not be obtained for the $\mathrm{Fe}_{25} \mathrm{Co}_{25} \mathrm{Ni}_{25}\left(\mathrm{Si}_{1-x} \mathrm{C}_{x}\right)_{25}$ HEAs and $\mathrm{Fe}_{75}\left(\mathrm{Si}_{1-x} \mathrm{C}_{x}\right)_{25}$ alloys. It was also confirmed that the saturation magnetization at room temperature of the HEAs is about a half that of the Fe-based amorphous alloys.
\end{abstract}

\section{KEY WORDS}

high entropy alloy, amorphous alloy, ferromagnetic material, glass-forming ability, magnetization

\section{Introduction}

In the last quarter century, research on bulk metallic glasses (BMGs), a new type of metallic materials with an amorphous structure and a large glass forming ability (GFA), has been rapidly developed $^{1-3)}$. Their unique properties have stimulated extensive research. Among them, the Fe-based BMGs have attracted attention as an industrial material owing to their good soft magnetic and mechanical properties ${ }^{4,5)}$.

On the other hand, high entropy alloys (HEAs) or equiatomic multi-component alloys that often form a single solid solution are developed slightly later than BMGs and share many similar superior properties with $\mathrm{BMGs}^{6}$. The HEAs are characterized by their high mixing (or configuration) entropy,

$$
\Delta S_{\text {mix }}=-R \sum_{i=1}^{N} c_{i} \operatorname{In} c_{i},
$$

where $R$ is the gas constant, $N$ the total number of the constituent elements and $c_{i}$ the atomic fraction of $i$-th element, respectively. In general, the high $\Delta S_{\text {mix }}$ in these alloys greatly reduce the free energy of simple solid-solution phases, especially at high temperatures, and may inhibit the formation of chemically-ordered intermetallic

* Corresponding author, E-mail: teruo_bitoh@akita-pu.ac.jp.

** The content of this article had been presented at JSPMIC2017. compounds. As a result, HEAs obtained by rapid quenching often contains topologically-simple but chemically-disordered solid solutions, nano-sized precipitate, and amorphous phases.

Recently, some ferromagnetic Fe-Co-Ni-based HEAs with an amorphous structure have been reported ${ }^{7,8)}$. However, there are few studies on the ferromagnetic Fe-Co-Ni-based amorphous HEAs, and the effects of high mixing entropy on structural, thermal and magnetic properties are still unclear. This paper aims to present the formation, structure, thermal and magnetic properties of high entropy $\mathrm{Fe}-\mathrm{Co}-\mathrm{Ni}-(\mathrm{B}, \mathrm{Si}, \mathrm{C})$ amorphous alloys in comparison with ternary Fe-based amorphous alloys and to investigate the effects of a high entropy on their fundamental properties.

\section{Experimental procedure}

The mixtures of pure $\mathrm{Fe}(99.99 \%)$, Co (99.9\%), Ni (99.9\%), B (99.5\%), Si (99.999\%), and C (99.5\%) were melted by an arc furnace in an Ar atmosphere. The rapidly-solidified ribbons with approximately $1 \mathrm{~mm}$ in width were prepared by a single-roller melt-spinning apparatus with a $\mathrm{Cu}$ wheel in an $\mathrm{Ar}$ atmosphere. The structure of the specimens was examined by X-ray diffractometry (XRD) with $\mathrm{Cu} K_{\alpha}$ incident radiation. The thermal properties of the alloys were investigated using a differential scanning calorimetry 
(DSC) with a heating rate of $0.67 \mathrm{~K} / \mathrm{s}$. The saturation mass magnetization $\left(\sigma_{\mathrm{s}}\right)$ was measured with a magnetic balance in an applied magnetic field $(H)$ up to $800 \mathrm{kA} / \mathrm{m}$ at room temperature.

\section{Results and discussion}

Fig. 1 shows the XRD profiles of the as-quenched $\mathrm{Fe}_{25} \mathrm{Co}_{25} \mathrm{Ni}_{25}\left(\mathrm{~B}_{1-x} \mathrm{Si}_{x}\right)_{25}$, $\mathrm{Fe}_{25} \mathrm{Co}_{25} \mathrm{Ni}_{25}\left(\mathrm{~B}_{1-x} \mathrm{C}_{x}\right)_{25}$ and $\mathrm{Fe}_{25} \mathrm{Co}_{25} \mathrm{Ni}_{25}\left(\mathrm{Si}_{1-x} \mathrm{C}_{x}\right)_{25}(x=0.3,0.5,0.7)$ HEAs with thickness of approximately $20 \mu \mathrm{m}$. The single amorphous structure could be obtained in the $\mathrm{Fe}_{25} \mathrm{Co}_{25} \mathrm{Ni}_{25}\left(\mathrm{~B}_{1-x} \mathrm{Si}_{x}\right)_{25}$ HEA system. In the $\mathrm{Fe}_{25} \mathrm{Co}_{25} \mathrm{Ni}_{25}\left(\mathrm{~B}_{1-x} \mathrm{C}_{x}\right)_{25}$ HEA system, the specimen with a single amorphous phase could be obtained when $x=0.3$. However, at $x=$ 0.5 and 0.7 , the specimens with a mixed phase of an amorphous and a crystalline could be prepared. An amorphous phase could not be obtained in the $\mathrm{Fe}_{25} \mathrm{Co}_{25} \mathrm{Ni}_{25}\left(\mathrm{Si}_{1-x} \mathrm{C}_{x}\right)_{25}$ HEA system. The XRD profiles of the as-quenched $\mathrm{Fe}_{75}\left(\mathrm{~B}_{1-x} \mathrm{Si}_{x}\right)_{25}, \mathrm{Fe}_{75}\left(\mathrm{~B}_{1-x} \mathrm{C}_{x}\right)_{25}$ and $\mathrm{Fe}_{75}\left(\mathrm{Si}_{1-x} \mathrm{C}_{x}\right)_{25}$ alloys with thickness of approximately $20 \mu \mathrm{m}$ are shown in Fig. 2 for comparison. The alloys with the single amorphous phase were obtained in the $\mathrm{Fe}_{75}\left(\mathrm{~B}_{1-x} \mathrm{Si}_{x}\right)_{25}$ system and the $\mathrm{Fe}_{75}\left(\mathrm{~B}_{0.7} \mathrm{C}_{0.3}\right)_{25}$ alloy. This result completely matched that of the HEA system. However, since a halo originates from an amorphous phase could be confirmed in the XRD profiles of the HEA alloy, the volume fraction of the amorphous phase of the $\mathrm{Fe}_{25} \mathrm{Co}_{25} \mathrm{Ni}_{25}\left(\mathrm{~B}_{1-x} \mathrm{C}_{x}\right)_{25}(x=0.5,0.7)$ HEAs is clearly higher than that of the $\mathrm{Fe}_{75}\left(\mathrm{~B}_{1-x} \mathrm{C}_{x}\right)_{25}(x=0.5,0.7)$ alloys.

Fig. 3 shows the DSC traces of the $\mathrm{Fe}_{25} \mathrm{Co}_{25} \mathrm{Ni}_{25}\left(\mathrm{~B}_{1-x} \mathrm{Si}_{x}\right)_{25}$ and $\mathrm{Fe}_{25} \mathrm{Co}_{25} \mathrm{Ni}_{25}\left(\mathrm{~B}_{1-x} \mathrm{C}_{x}\right)_{25}(x=0.3,0.5,0.7)$ HEAs with thickness of approximately $20 \mu \mathrm{m}$. The DSC traces of the $\mathrm{Fe}_{75}\left(\mathrm{~B}_{1-x} \mathrm{Si}_{x}\right)_{25}(x=0.3$,

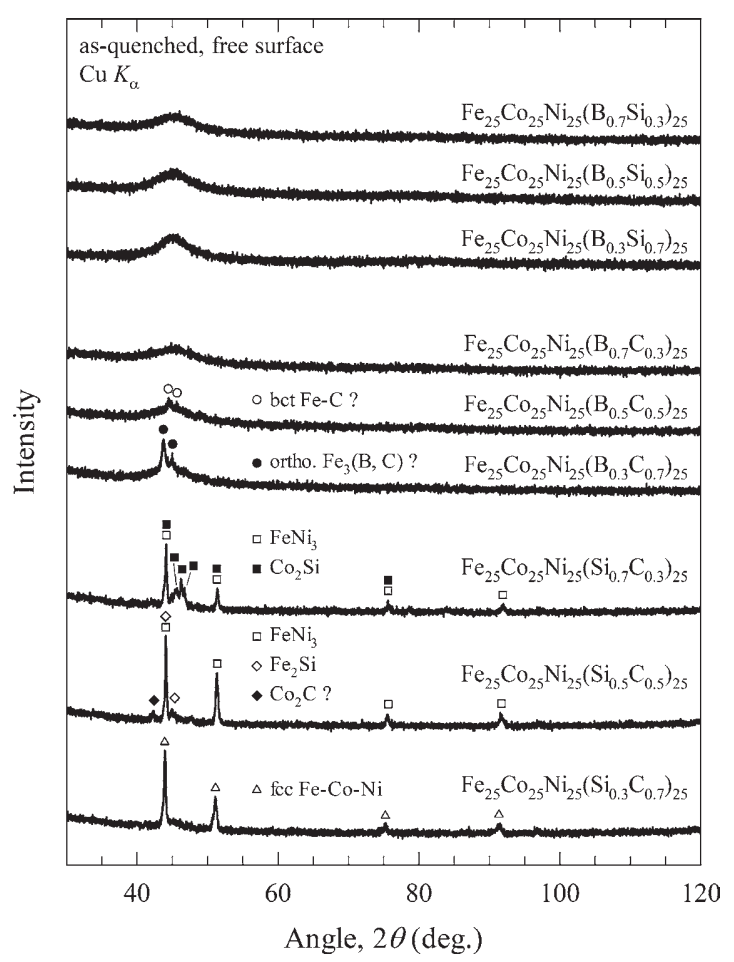

Fig. 1 XRD profiles taken from free surface of as-quenched $\mathrm{Fe}_{25} \mathrm{Co}_{25} \mathrm{Ni}_{25}\left(\mathrm{~B}_{1-x} \mathrm{Si}_{x}\right)_{25}$, $\mathrm{Fe}_{25} \mathrm{Co}_{25} \mathrm{Ni}_{25}\left(\mathrm{~B}_{1-x} \mathrm{C}_{x}\right)_{25}$ and $\mathrm{Fe}_{25} \mathrm{Co}_{25} \mathrm{Ni}_{25}\left(\mathrm{Si}_{1-x} \mathrm{C}_{x}\right)_{25}(x=0.3,0.5,0.7)$ high entropy alloys with thickness of approximately $20 \mu \mathrm{m}$.

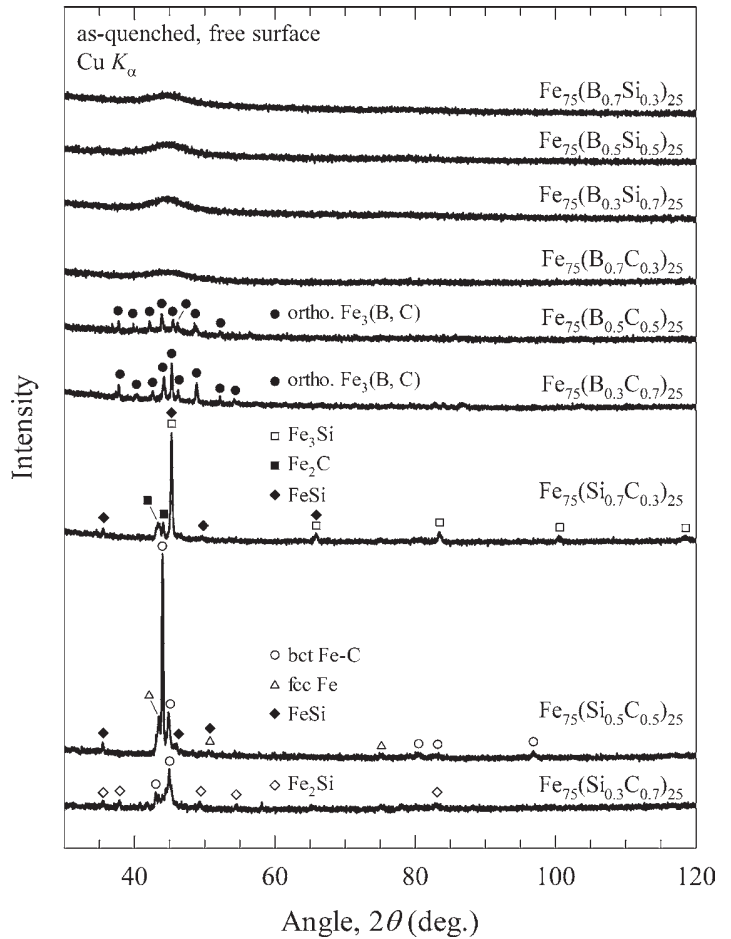

Fig. $2 \mathrm{XRD}$ profiles taken from free surface of as-quenched $\mathrm{Fe}_{75}\left(\mathrm{~B}_{1-x} \mathrm{Si}_{x}\right)_{25}$, $\mathrm{Fe}_{75}\left(\mathrm{~B}_{1-x} \mathrm{C}_{x}\right)_{25}$ and $\mathrm{Fe}_{75}\left(\mathrm{Si}_{1-x} \mathrm{C}_{x}\right)_{25}$ alloys with thickness of approximately $20 \mu \mathrm{m}$.

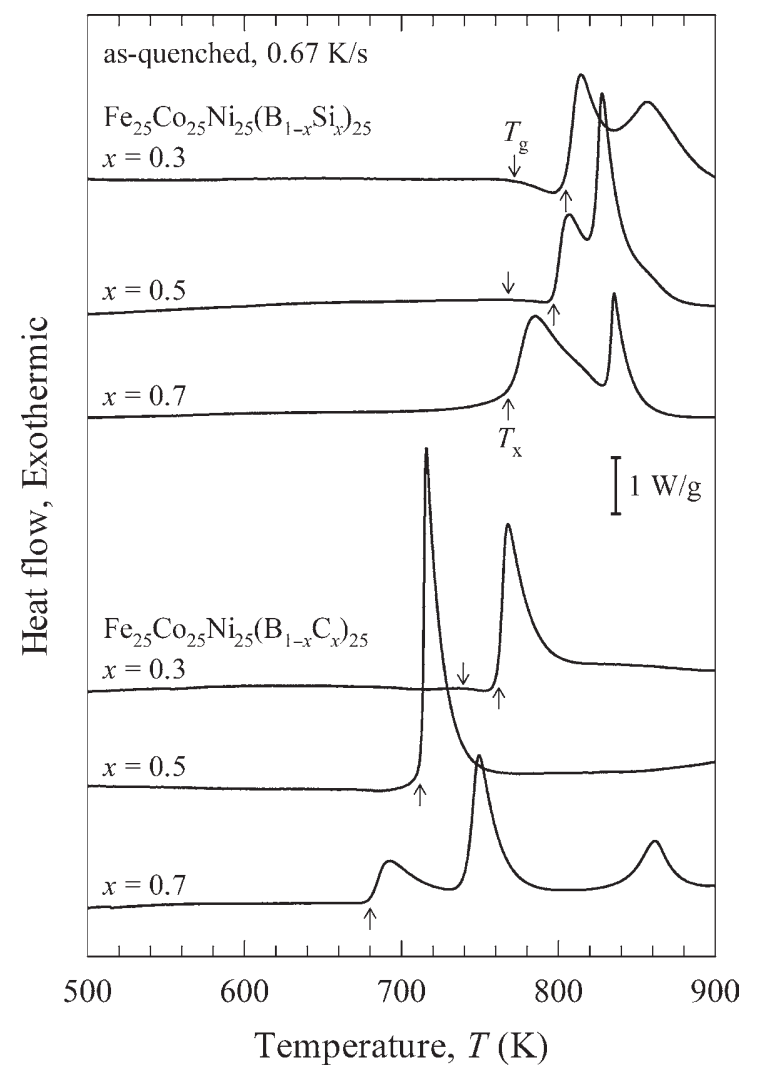

Fig. 3 DSC traces of as-quenched $\mathrm{Fe}_{25} \mathrm{Co}_{25} \mathrm{Ni}_{25}\left(\mathrm{~B}_{1-x} \mathrm{Si}_{x}\right)_{25}$ and $\mathrm{Fe}_{25} \mathrm{Co}_{25} \mathrm{Ni}_{25}\left(\mathrm{~B}_{1-x} \mathrm{C}_{x}\right)_{25}$ $(x=0.3,0.5,0.7)$ high entropy alloys with thickness of approximately $20 \mu \mathrm{m}$. The arrows indicate the glass transition $\left(T_{\mathrm{g}}\right)$ and crystallization $\left(T_{\mathrm{x}}\right)$ temperatures of the alloys. 
0.5, 0.7) and $\mathrm{Fe}_{75}\left(\mathrm{~B}_{0.7} \mathrm{C}_{0.3}\right)_{25}$ alloys with thickness of approximately $20 \mu \mathrm{m}$ are shown in Fig. 4 for comparison. Some large exothermic peaks are observed in the DSC curve of all the alloys. This means that the metastable amorphous phases transformed into stable crystalline phases with increasing temperature. Two or three exothermic peaks are observed in the DSC curve of the $\mathrm{Fe}_{25} \mathrm{Co}_{25} \mathrm{Ni}_{25}\left(\mathrm{~B}_{1-x} \mathrm{Si}_{x}\right)_{25}(x=0.3,0.5,0.7), \mathrm{Fe}_{25} \mathrm{Co}_{25} \mathrm{Ni}_{25}\left(\mathrm{~B}_{0.3} \mathrm{C}_{0.7}\right)_{25}$ and $\mathrm{Fe}_{75}\left(\mathrm{~B}_{1-x} \mathrm{Si}_{x}\right)_{25}(x=0.5,0.7)$ alloys. The exothermic peaks at higher temperatures correspond to the crystallization of the residual amorphous phase or the transformation of the metastable crystalline phases to the stable crystalline ones. An endothermic reaction corresponds to the glass transition prior to the large exothermic reaction due to the crystallization can be seen for the $\mathrm{Fe}_{25} \mathrm{Co}_{25} \mathrm{Ni}_{25}\left(\mathrm{~B}_{0.7} \mathrm{Si}_{0.3}\right)_{25}, \mathrm{Fe}_{25} \mathrm{Co}_{25} \mathrm{Ni}_{25}\left(\mathrm{~B}_{0.5} \mathrm{Si}_{0.5}\right)_{25}$ and $\mathrm{Fe}_{25} \mathrm{Co}_{25} \mathrm{Ni}_{25}\left(\mathrm{~B}_{0.7} \mathrm{C}_{0.3}\right)_{25}$ HEAs. On the contrary, no glass transition is observed in the $\mathrm{Fe}_{75}\left(\mathrm{~B}_{1-x} \mathrm{Si}_{x}\right)_{25}$ and $\mathrm{Fe}_{75}\left(\mathrm{~B}_{1-x} \mathrm{C}_{x}\right)_{25}$ alloys. A small endothermic reaction due to the ferromagnetic to paramagnet phase transition at the Curie temperature $\left(T_{\mathrm{C}}\right)$, which could not be found in the HEAs, could be recognized around $700 \sim 720 \mathrm{~K}$. As described later, this is due to the much larger magnetization of the $\mathrm{Fe}_{75}\left(\mathrm{~B}_{1-x} \mathrm{Si}_{x}\right)_{25}$ and $\mathrm{Fe}_{75}\left(\mathrm{~B}_{1-x} \mathrm{C}_{x}\right)_{25}$ alloys than that of the HEAs; i.e., the change in magnetic entropy due to the phase transition of the Fe-based alloys is much larger than that of the HEAs.

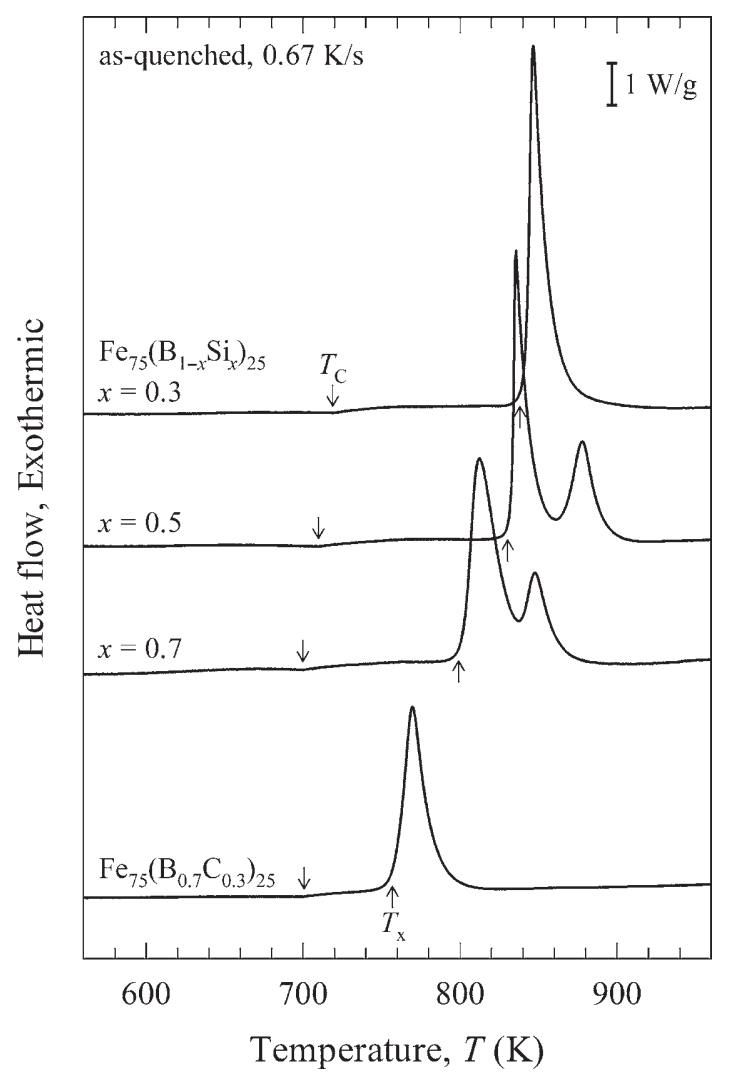

Fig. 4 DSC traces of as-quenched $\mathrm{Fe}_{75}\left(\mathrm{~B}_{1-x} \mathrm{Si}_{x}\right)_{25}(x=0.3,0.5,0.7)$ and $\mathrm{Fe}_{75}\left(\mathrm{~B}_{0.7} \mathrm{C}_{0.3}\right)_{25}$ alloys with thickness of approximately $20 \mu \mathrm{m}$. The arrows indicate the Curie $\left(T_{\mathrm{C}}\right)$ and crystallization $\left(T_{\mathrm{x}}\right)$ temperatures of the alloys.
The glass-forming ability of the alloys was evaluated. The specimens with various thicknesses were prepared by adjusting the wheel speed of the melt-spinning apparatus. Figs. 5 and 6 shows the XRD profiles taken from free surface of as-quenched HEA and Fe-based

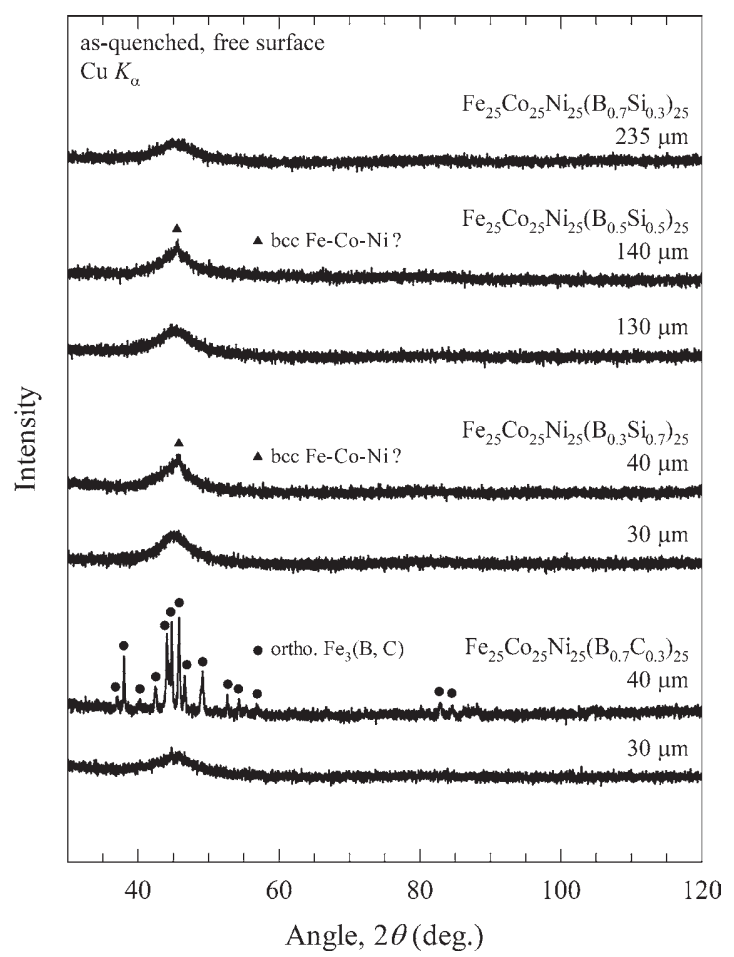

Fig. 5 XRD profiles taken from free surface of as-quenched $\mathrm{Fe}_{25} \mathrm{Co}_{25} \mathrm{Ni}_{25}\left(\mathrm{~B}_{1-x} \mathrm{Si}_{x}\right)_{25}$ and $\mathrm{Fe}_{25} \mathrm{Co}_{25} \mathrm{Ni}_{25}\left(\mathrm{~B}_{1-x} \mathrm{C}_{x}\right)_{25}(x=0.3,0.5,0.7)$ high entropy alloys with various thicknesses.

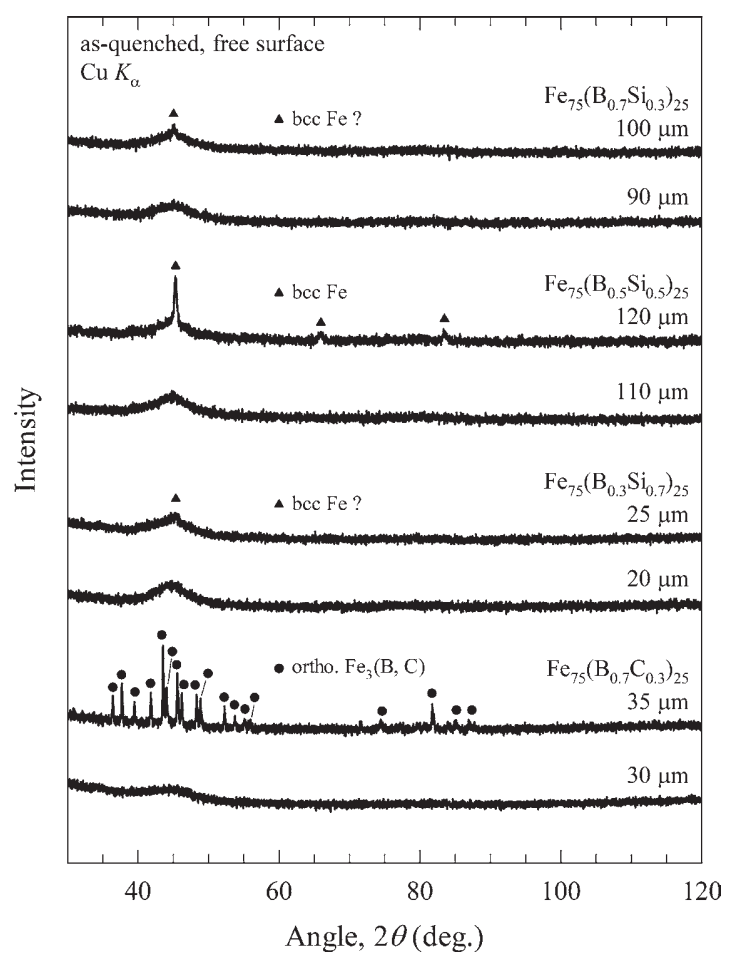

Fig. 6 XRD profiles taken from free surface of as-quenched $\mathrm{Fe}_{75}\left(\mathrm{~B}_{1-x} \mathrm{Si}_{x}\right)_{25}$ $(x=0.3,0.5,0.7)$ and $\mathrm{Fe}_{75}\left(\mathrm{~B}_{0.7} \mathrm{C}_{0.3}\right)_{25}$ alloys with various thicknesses 
alloys with various thicknesses, respectively. It is noticed that the critical thickness for amorphous formation $\left(t_{c}\right)$ of HEAs is significantly larger than that of the Fe-based alloys.

The parameters of the alloys expected to be related to the formation of the amorphous phase are shown in Table 1. Here, the mixing enthalpy of the alloys are calculated by ${ }^{9,10)}$

$$
\Delta H_{\text {mix }}=4 \sum_{j \neq i}^{N} \sum_{i=1}^{N} \Delta H_{i j} C_{i} C_{j},
$$

where $\Delta H_{i j}$ is the mixing enthalpy at the binary equiatomic alloy of $i$-th and $j$-th element. The atomic size difference is expressed as ${ }^{11)}$

$$
\delta=100 \sqrt{\sum_{i=1}^{N} c_{i}\left(1-\frac{r_{i}}{\bar{r}}\right)^{2}},
$$

where $r_{i}$ is the atomic radius of $i$-th element and

$$
\bar{r}=\sum_{i=1}^{N} c_{i} r_{i} .
$$

The values of the atomic radius are used in ref. 12. Fe, Co and $\mathrm{Ni}$ have similar atomic radius and the mixing enthalpy between other elements. Therefore, the values of $\Delta H_{\text {mix }}$ and $\delta$ of Fe-based alloys and HEAs are almost the same, as shown in Table 1. However, $\Delta S_{\text {mix }}$ of HEAs has increased more than twice that of the Fe-based alloys. Guo and Liu pointed out that there is a strong correlation between the increase of $\Delta S_{\text {mix }}$ and the decrease of the critical cooling rate for amorphous formation ${ }^{13)}$. This means the large $\Delta S_{\text {mix }}$ is preferable for achieving a large GFA.

Next, the properties of $\mathrm{Fe}_{25} \mathrm{Co}_{25} \mathrm{Ni}_{25}\left(\mathrm{~B}_{x} \mathrm{Si}_{y} \mathrm{C}_{z}\right)_{25}$ alloys have been investigated with the intent of improving GFA by increasing $\Delta S_{\text {mix }}$.
Fig. 7 shows the compositional dependence of the as-quenched structure and the width of the supercooled liquid region $\left(\Delta T_{\mathrm{x}}=T_{\mathrm{x}}\right.$ - $T_{\mathrm{g}}$, where $T_{\mathrm{x}}$ and $T_{\mathrm{g}}$ are the crystallization and glass transition temperatures, respectively) of the $\mathrm{Fe}_{25} \mathrm{Co}_{25} \mathrm{Ni}_{25}\left(\mathrm{~B}_{x} \mathrm{Si}_{y} \mathrm{C}_{z}\right)_{25}$ HEAs. The solid circles show the alloys exhibiting the glass transition. The glass transition is recognized in a composition range of $x=$ $0.4 \sim 0.7, y=0 \sim 0.5$ and $z=0 \sim 0.4$. It should be noted that the larger $\Delta T_{\mathrm{x}}$ than $30 \mathrm{~K}$ is obtained with the alloys along $x=0.4$.

Fig. 8 shows the relation between $\Delta H_{\text {mix }}$ and $\delta$ for the HEAs and the Fe-based alloys in the present study. According to the results of Guo and $\mathrm{Liu}^{13)}$, the formation region of HE-BMGs is determined

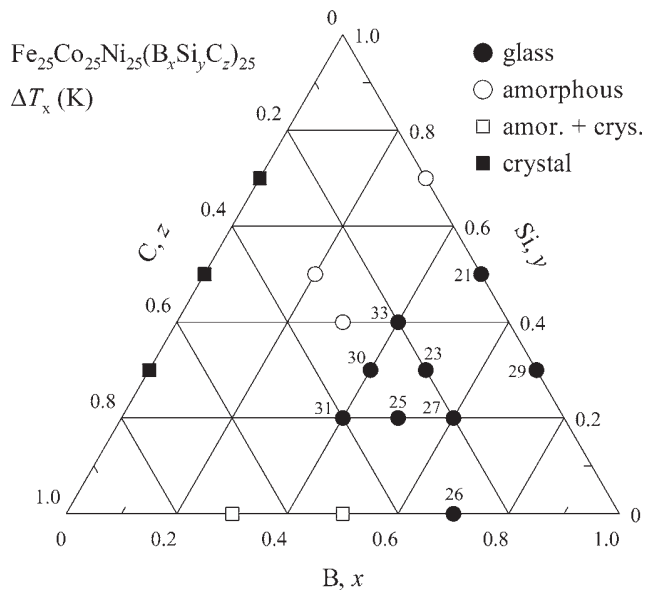

Fig. 7 Compositional dependence of as-quenched structure and width of supercooled liquid region $\left(\Delta T_{\mathrm{x}}=T_{\mathrm{x}}-T_{\mathrm{g}}\right)$ of $\mathrm{Fe}_{25} \mathrm{Co}_{25} \mathrm{Ni}_{25}\left(\mathrm{~B}_{x} \mathrm{Si}_{y} \mathrm{C}_{z}\right)_{25}$ high entropy alloys.

\begin{tabular}{|c|c|c|c|c|c|c|c|c|}
\hline & \multirow{4}{*}{$\begin{array}{l}\mathrm{Fe}_{25} \mathrm{Co}_{25} \mathrm{Ni}_{25}\left(\mathrm{~B}_{0.7} \mathrm{Si}_{0.3}\right)_{25} \\
\mathrm{Fe}_{25} \mathrm{Co}_{25} \mathrm{Ni}_{25}\left(\mathrm{~B}_{0.5} \mathrm{Si}_{0.5}\right)_{25} \\
\mathrm{Fe}_{25} \mathrm{Co}_{25} \mathrm{Ni}_{25}\left(\mathrm{~B}_{0.3} \mathrm{Si}_{0.7}\right)_{25}\end{array}$} & \multirow{4}{*}{$\begin{array}{l}\text { Structure } \\
\text { glass } \\
\text { glass } \\
\text { amorphous }\end{array}$} & \multicolumn{2}{|c|}{$\begin{array}{l}\text { Mixing enthalpy, } \\
\Delta H_{\text {mix }}(\mathrm{kJ} / \mathrm{mol})\end{array}$} & \multicolumn{2}{|c|}{$\begin{array}{l}\text { Mixing entropy, } \\
\qquad \Delta S_{\mathrm{mix}} / R\end{array}$} & \multicolumn{2}{|c|}{$\begin{array}{l}\text { Atomic size } \\
\text { polydispersity, } \\
\delta(\%)\end{array}$} \\
\hline \multirow{9}{*}{ High entropy alloys } & & & -22.9 & $(+2.9 \%)$ & 1.54 & $(+115 \%)$ & 11.7 & $(+1.5 \%)$ \\
\hline & & & -25.0 & $(+5.3 \%)$ & 1.56 & $(+112 \%)$ & 10.1 & $(+1.6 \%)$ \\
\hline & & & -26.8 & $(+7.4 \%)$ & 1.54 & $(+115 \%)$ & 8.1 & $(+1.9 \%)$ \\
\hline & $\mathrm{Fe}_{25} \mathrm{Co}_{25} \mathrm{Ni}_{25}\left(\mathrm{~B}_{0.7} \mathrm{C}_{0.3}\right)_{25}$ & glass & -24.1 & $(-5.4 \%)$ & 1.54 & $(+115 \%)$ & 15.3 & $(+1.2 \%)$ \\
\hline & $\mathrm{Fe}_{25} \mathrm{Co}_{25} \mathrm{Ni}_{25}\left(\mathrm{~B}_{0.5} \mathrm{C}_{0.5}\right)_{25}$ & amor. + crys. & -27.0 & $(-7.3 \%)$ & 1.56 & $(+112 \%)$ & 16.2 & $(+1.1 \%)$ \\
\hline & $\mathrm{Fe}_{25} \mathrm{Co}_{25} \mathrm{Ni}_{25}\left(\mathrm{~B}_{0.3} \mathrm{C}_{0.7}\right)_{25}$ & amor. + crys. & -29.8 & $(-8.8 \%)$ & 1.54 & $(+115 \%)$ & 17.1 & $(+1.1 \%)$ \\
\hline & $\mathrm{Fe}_{25} \mathrm{Co}_{25} \mathrm{Ni}_{25}\left(\mathrm{Si}_{0.7} \mathrm{C}_{0.3}\right)_{25}$ & crystalline & -32.4 & $(+2.3 \%)$ & 1.54 & $(+115 \%)$ & 10.5 & $(+1.2 \%)$ \\
\hline & $\mathrm{Fe}_{25} \mathrm{Co}_{25} \mathrm{Ni}_{25}\left(\mathrm{Si}_{0.5} \mathrm{C}_{0.5}\right)_{25}$ & crystalline & -33.7 & $(-1.8 \%)$ & 1.56 & $(+112 \%)$ & 13.3 & $(+1.0 \%)$ \\
\hline & $\mathrm{Fe}_{25} \mathrm{Co}_{25} \mathrm{Ni}_{25}\left(\mathrm{Si}_{0.3} \mathrm{C}_{0.7}\right)_{25}$ & crystalline & -34.2 & $(-5.5 \%)$ & 1.54 & $(+115 \%)$ & 15.5 & $(+1.0 \%)$ \\
\hline \multirow{9}{*}{ Fe-based alloys } & $\mathrm{Fe}_{75}\left(\mathrm{~B}_{0.7} \mathrm{Si}_{0.3}\right)_{25}$ & amorphous & -22.3 & & 0.72 & & 11.6 & \\
\hline & $\mathrm{Fe}_{75}\left(\mathrm{~B}_{0.5} \mathrm{Si}_{0.5}\right)_{25}$ & amorphous & -23.8 & & 0.74 & & 9.9 & \\
\hline & $\mathrm{Fe}_{75}\left(\mathrm{~B}_{0.3} \mathrm{Si}_{0.7}\right)_{25}$ & amorphous & -25.0 & & 0.72 & & 7.9 & \\
\hline & $\mathrm{Fe}_{75}\left(\mathrm{~B}_{0.7} \mathrm{C}_{0.3}\right)_{25}$ & amorphous & -25.4 & & 0.72 & & 15.1 & \\
\hline & $\mathrm{Fe}_{75}\left(\mathrm{~B}_{0.5} \mathrm{C}_{0.5}\right)_{25}$ & crystalline & -29.1 & & 0.74 & & 16.0 & \\
\hline & $\mathrm{Fe}_{75}\left(\mathrm{~B}_{0.3} \mathrm{C}_{0.7}\right)_{25}$ & crystalline & -32.6 & & 0.72 & & 16.9 & \\
\hline & $\mathrm{Fe}_{75}\left(\mathrm{Si}_{0.7} \mathrm{C}_{0.3}\right)_{25}$ & crystalline & -31.7 & & 0.72 & & 10.3 & \\
\hline & $\mathrm{Fe}_{75}\left(\mathrm{Si}_{0.5} \mathrm{C}_{0.5}\right)_{25}$ & crystalline & -34.3 & & 0.74 & & 13.1 & \\
\hline & $\mathrm{Fe}_{75}\left(\mathrm{Si}_{0.3} \mathrm{C}_{0.7}\right)_{25}$ & crystalline & -36.2 & & 0.72 & & 15.4 & \\
\hline
\end{tabular}

Table 1 Parameters of high entropy alloys and Fe-based alloys. The values in the parentheses of the HEA alloys indicate the ratio to that of the Fe-based alloys having the same contents of the metalloid elements. 


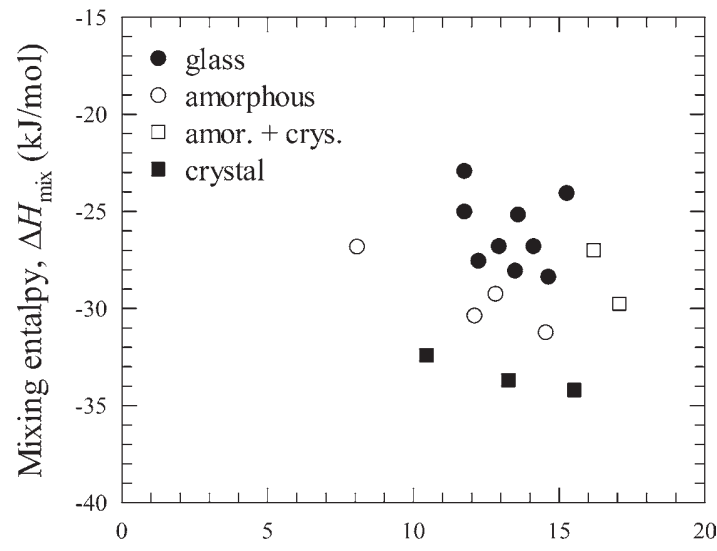

Atomic size polydispersity, $\delta(\%)$

Fig. 8 Relation between mixing enthalpy $\left(\Delta H_{\text {mix }}\right)$, atomic size polydispersity $(\delta)$ and as-quenched structure for high entropy alloys.

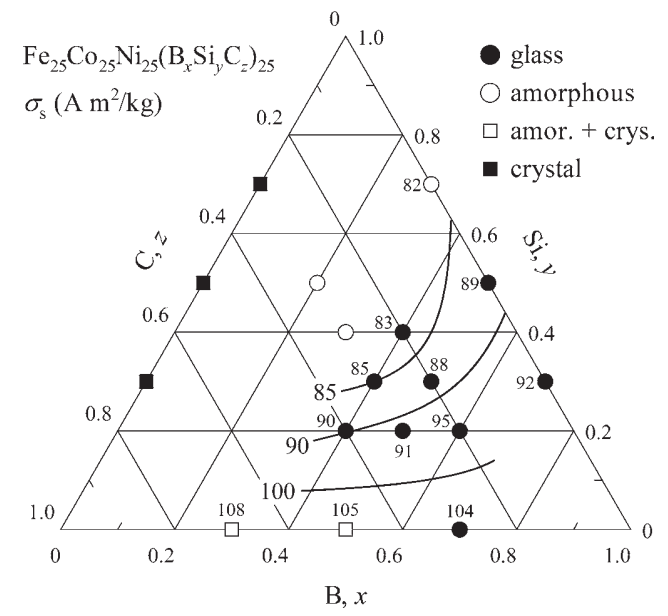

Fig. 9 Compositional dependence of saturation mass magnetization $\left(\sigma_{\mathrm{s}}\right)$ in an as-quenched state of $\mathrm{Fe}_{25} \mathrm{Co}_{25} \mathrm{Ni}_{25}\left(\mathrm{~B}_{x} \mathrm{Si}_{y} \mathrm{C}_{z}\right)_{25}$ high entropy alloys.

by $\Delta H_{\text {mix }}$ and $\delta$, i.e., $-49 \leq \Delta H_{\text {mix }} \leq-5.5 \mathrm{~kJ} / \mathrm{mol}$ and $\delta \geq 9$. However, the HE-BMG formation region of the present alloy system is clearly narrower than their result. First, no amorphous phase is formed in $\Delta H_{\text {mix }} \leq-32 \mathrm{~kJ} / \mathrm{mol}$. The single amorphous structure could not be obtained in $\delta \geq 16$. The alloys having the glass transition are obtained only in a narrow region of $-29 \leq \Delta H_{\text {mix }} \leq-22 \mathrm{~kJ} / \mathrm{mol}$ and $11 \leq \delta \leq 16$.

Fig. 9 shows the compositional dependence of the mass magnetization $\left(\sigma_{\mathrm{s}}\right)$ of the $\mathrm{Fe}_{25} \mathrm{Co}_{25} \mathrm{Ni}_{25}\left(\mathrm{~B}_{x} \mathrm{Si}_{y} \mathrm{C}_{z}\right)_{25}$ HEAs in an as-quenched state. The high entropy glassy alloys have low magnetization of $83 \sim 104 \mathrm{~A} \mathrm{~m}^{2} / \mathrm{kg}$. These values are roughly half those of the Fe-based amorphous alloys $\left(163 \sim 178 \mathrm{~A} \mathrm{~m}^{2} / \mathrm{kg}\right.$ ). The magnetization shows a tendency to decrease with increasing Si content similar to that of the Fe-based amorphous alloys ${ }^{14,15)}$. This is due to decrease of the concentration of the magnetic elements per unit mass because $\mathrm{Si}$ has larger atomic radius and atomic mass than $\mathrm{B}$ and $\mathrm{C}$. It is known that the atomic magnetic moment of ( $\mathrm{Fe}, \mathrm{Co}, \mathrm{Ni})$-metalloid amorphous alloy systems decreases in the order of $\mathrm{Fe}\left(\sim 2 \mu_{\mathrm{B}}\right.$, where $\mu_{\mathrm{B}}$ is the Bohr magneton), Co $\left(\sim 1.2 \mu_{\mathrm{B}}\right)$ and $\mathrm{Ni}\left(\sim 0 \mu_{\mathrm{B}}\right)$ with changes of the $3 \mathrm{~d}$-electron numbers ${ }^{16)}$. Therefore, it is unavoidable that the magnetization of the HEAs is significantly inferior to the Fe-based amorphous alloys.

The present high entropy amorphous alloys are unsuitable for power applications such as transformers because of their low magnetization. However, the present high entropy amorphous alloys have rather high GFA though they do not contain transition metal elements such as $\mathrm{Zr}$, Nb, Mo, etc. and P. It is well known that these elements improve GFA of (Fe, $\mathrm{Co}, \mathrm{Ni}$ )-based amorphous alloys ${ }^{4,5)}$. However, the transition metal elements are expensive, and some elements such as $\mathrm{Zr}$ are difficult to prevent oxidation. On the other hand, the vapor pressure of $\mathrm{P}$ is quite high, and the pollution of crucibles and of furnaces by $\mathrm{P}$ cause various problems including contamination in the manufacturing premises. The high GFA will eases restrictions on the size and the shape of the alloy specimens. It has also been reported that Fe-Co-Ni-based high entropy amorphous alloys exhibit good mechanical properties ${ }^{7,8)}$. Therefore, it is expected that the present Fe-Co-Ni-based high entropy amorphous alloys can be used for some applications such as magnetic shielding.

\section{Conclusion}

The ferromagnetic Fe-Co-Ni-metalloid high entropy alloys (HEAs) with an amorphous structure were prepared by single-roller melt-spinning method and evaluated their thermal and magnetic properties. The Fe-based alloys in which all the ferromagnetic metal elements were substituted with Fe were prepared for comparison. The HEAs show much higher glass-forming ability (GFA) than that of the Fe-based alloys. The dependence of GFA on kinds and ratio of metalloid elements shows a similar tendency in the HEAs and the Fe-based alloys. The saturation mass magnetization at room temperature of the HEAs is about a half that of the Fe-based amorphous alloys. It is also confirmed the magnetization of HEAs shows a tendency to decrease with increasing Si content similar to that of the Fe-based amorphous alloys.

\section{References}

1) A. Inoue: Acta Mater., 48 (2000) 279-306

2) A. Inoue, A. Takeuchi: Acta Mater., 59 (2011) 2243-2267.

3) A. Inoue: Engineering, 1 (2015) 185-191.

4) A. Inoue, A. Takeuchi, B. Shen: Mater. Trans., 42 (2001) 970978.

5) C. Suryanarayana, A. Inoue: Int. Mater. Rev., 58 (2013) 131166.

6) Y. F. Ye, Q. Wang, J. Lu, C. T. Liu, Y. Yang: Mater. Today, 19 (2016) 349-362.

7) T. Qi, Y. Li, A. Takeuchi, G. Xie, H. Miao, W. Zhang: Intermetallics, 66 (2015) 8-12.

8) Y. Li, W. Zhang, T. Qi: J. Alloys Comp., 693 (2017) 25-31.

9) F. R. de Boer, R. Boom, W. C. M. Mattens, A. R. Miedema, A. 
K. Niessen: Cohesion in Metals, North-Holland, Amsterdam, 1988.

10) A. Takeuchi, A. Inoue: Mater. Trans., 46 (2005) 2817-2829.

11) Y. Zhang, Y. J. Zhou, J. P. Lin, G. L. Chen, P. K. Liaw: Adv. Eng. Mater., 10 (2008) 534-538.

12) J. Emsley: The Elements, 3rd ed., Oxford University, Oxford, 1998.
13) S. Guo, C. T. Liu: Prog. Nat. Sic., 21 (2011) 433-446.

14) F. Luborsky, J. Becker, J. Walter, H. Liebermann: IEEE Trans. Magn. MAG-15 (1979) 1146-1149.

15) F. Luborsky, J. Walter: IEEE Trans. Magn. MAG-16 (1980) 572-574.

16) See, e.g., P. Hansen: Magnetic Amorphous alloys, in Handbook of Magnetic Materials, vol. 6, Elsevier (1991) 289-452. 